DOI: https://doi.org/10.24867/13CG04Budimac

\title{
PROCENA STANJA I ENERGETSKA SANACIJA POSLOVNE ZGRADE „NOVITET” U NOVOM SADU
}

\section{ASSESSMENT OF CONDITION AND ENERGY RENOVATION OF BUSINESS BUILDING "NOVITET"' IN NOVI SAD}

\author{
Jakov Budimac, Fakultet tehničkih nauka, Novi Sad
}

\begin{abstract}
Oblast - GRAĐEVINARSTVO
Kratak sadržaj - Rad se sastoji iz teorijskog i praktčnog dela. U teorijskom delu su ukratko opisane ventilisane fasade, a potom su detaljnije opisani Aquapanel sistemi ventilisanih fasada. U praktičnom delu je urađena procena stanja objekta "Novitet u Novom Sadu. Potom urađen proračun energetske efikasnosti objekta. Nakon predloženih mera sanacije objekta, urađen je proračun energetske efikasnosti saniranog objekta i upotređeni su razredi energetske efikasnosti objekta pre $i$ nakon energetske obnove objekta.
\end{abstract}

Ključne reči: Ventilisane fasade, Aquapanel, Energetska efikasnost, Sanacija

\begin{abstract}
The paper consists of a theoretical and a practical part. In the theoretical part a short description of ventilated facades was done. Then, the Aquapanel ventilated facade systems were described in detail. The assessment of the condition of building "Novitet", which is located in Novi Sad was carried out. Furthermore, the energy efficiency calculation for the existing state of the building was calculated. After application of the rehabilitation measures, the new energy efficiency class was calculated. Finally, the two classes were compared.
\end{abstract}

Keywords: Ventilated facades, Aquapanel, Energy efficiency, Rehabilitation

\section{AQUAPANEL SISTEMI VENTILISANIH FASADA}

\subsection{Ventilisane fasade}

Suština ventilisane fasade jeste sloj vazduha (slobodni prostor) između spoljne fasadne obloge i zida objekta. Glavna uloga vazdušnog sloja u ventilisanoj fasadi jeste ostvarivanje nesmetane cirkulacije vazduha, koja omogućava odvođenje vlage iz objekta, kao i vode koja eventualno može da prodre kroz spojnice fasadne obloge. Leti, sloj za ventilaciju (dodatno, uz izolaciju), sprečava prodiranje toplote u unutrašnjost objekta. Zimi predstavlja dodatni toplotni izolator, kao i dodatnu zaštitu od atmosferskih uticaja. Minimalan sloj vazduha kako bi se ostvarila cirkulacija vazduha jeste $2 \mathrm{~cm}$. Otvori za ventilaciju po visini zida, za ulaz i izlaz vazduha, treba da budu minimalne površine $50 \mathrm{~cm}^{2}$ po dužnom metru zida.

\section{NAPOMENA:}

Ovaj rad proistekao je iz master rada čiji mentor je bila dr Mirjana Malešev, red. prof.
Ventilisane fasade se sastoje iz više elemenata, a to su noseća potkonstrukcija, termoizolacija, sloj za ventilaciju, spoljna fasadna obloga [3].

\subsection{Aquapanel sistemi fasada}

Aquapanel sistemi fasada su posebna grupa fasada koje koriste Aquapanel cementne ploče kao fasadnu oblogu, dok se kao termoizolacija koristi najčešće kamena vuna. Između izolacije i završnog sloja se može nalaziti ventilacioni sloj vazduha od najmanje $2 \mathrm{~cm}$ u kom slučaju se radi o ventilisanim fasadama.

Aquapanel ploče su napravljene od portland cementa i ekspandirane gline, i obostrano su ojačane mrežom od staklenih vlakana. Ploče su pričvršćene za potkonstrukciju, čiji se statički sistem određuje iz analize opterećenja (sopstvena težina ploča, vetar...).

Aquapanel sistemi su se pokazali bolji u odnosu na klasične ETICS fasade u pogledu građevinske fizike, arhitektonske slobode, cene i uticaja na okolinu.

Fasadni sistemi koji koriste Aquapanel ploče se mogu podeliti u dva osnovna tipa:

- pregradni zidovi u skeletnim konstrukcijama (Armiranobetonska konstrukcija npr.) i

- klasične ventilisane fasade koje se instaliraju preko zidova (opeka, beton).

Postoji 12 različitih tipova instaliranja Aquapanel fasada, podeljenih u 5 sistema:

- sistem sa duplom potkonstrukcijom,

- sistem sa jednostrukom potkonstrukcijom,

- sistem klasične ventilisane fasade,

- sistem sa drvenim okvirom i

- sistem sa čeličnom konstrukcijom [4].

\subsection{Ventilisana Aquapanel fasada}

Ova vrsta fasade je debljine $230.5 \mathrm{~mm}$ sa težinom od 30.1 $\mathrm{kg} / \mathrm{m}^{2}$. Klasa zapaljivosti je A2, dok je za montiranje jednog $\mathrm{m}^{2}$ potrebno 85 minuta.

Ove vrednosti mogu varirati u zavisnosti od debljine termoizolacionog materijala. Fasade ovog tipa se najčešće izvode pri renoviranju i energetskoj sanaciji objekata građenih u masivnom konstruktivnom sistemu (slika 1). Obezbeđuju odvajanje temperaturne izolacije i klimatske zaštite objekta [4]. 


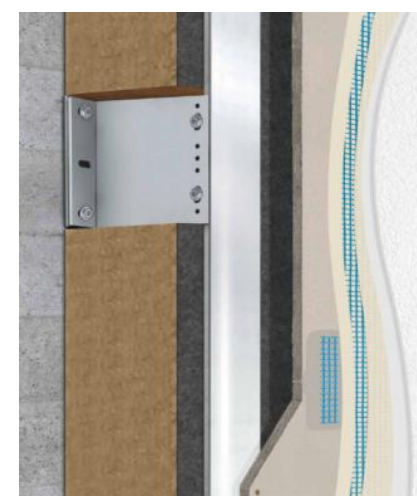

Slika 1. Izgled Aquapanel ventilisane fasade

\section{PROCENA STANJA OBJEKTA}

\subsection{Tehnički opis konstrukcije}

Objekat "Novitet" nalazi se u ulici Futoški put, broj 51 u Novom Sadu (slika 2). Projektovan je 1960. godine, za potrebe tekstilne industije. Tada je po funkciji bio podeljen na dva dela - halu sa magacinima i aneksni deo za potrebe proizvodnog dela. Danas se prostorije objekta iznajmljuju poslodavcima, koji nezavisno upravljaju svojim delom prostora. Analiziran će biti samo aneksni deo objekta.

Objekat je projektovan tako da je konstruktivni sistem prizemlja mešavina masivnog i skeletnog sistema (noseći fasadni zidovi debljina $25 \mathrm{~cm}$ i $38 \mathrm{~cm}$ i armiranobetonski stubovi kružnog i kvadratnog poprečnog preseka različitih dimenzija, unutar objekta). Prvi i drugi sprat su projektovani u skeletnom sistemu sa pločama oslonjenim na stubove kružnih i pravougaonih poprečnih preseka. Noseći zidovi u prizemlju su ukrućeni horizontalnim i vertikalnim serklažima od armiranog betona. Međuspratne konstrukcije su TM tavanice debljine $19 \mathrm{~cm}$ koje nose u jednom pravcu. Međuspratne konstrukcije se oslanjaju na armiranobetonske grede pravougaonog poprečnog preseka u jednom pravcu a ojačane su i gredama u drugom pravcu, koje se oslanjaju na stubove. Ploča prizemlja je armiranobetonska ploča debljine 12 $\mathrm{cm}$. Krovna konstrukcija je takodje TM konstrukcija, na kojoj se završnim slojevima obrazuje pad od manje od $1 \%$. Fundiranje objekta izvedeno na mešavini temelja samaca i trakastih temelja.

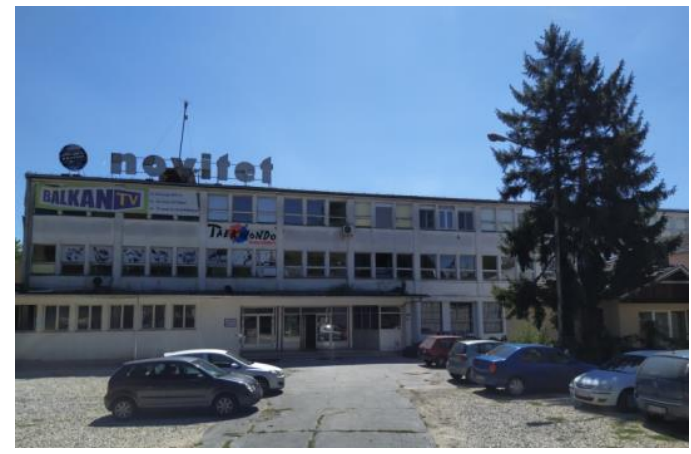

Slika 2. Izgled glavne fasade objekta

\subsection{Vizuelni pregled objekta i analiza uočenih oštećenja}

Cilj vizuelnog pregleda jeste proveravanje geometrije objekta i dimenzija konstruktivnih elemenata, registrovanje i klasifikacija vidljivih oštećenja, ucrtavanje u pripremljene podloge $\mathrm{i}$ fotografisanje karakterističnih defekata i oštećenja, odnosno, glavni cilj jeste - dobijanje što više relevantnih informacija potrebnih za formiranje zaključka o stanju konstrukcije. Nakon obavljenog vizuelnog pregleda i dokumentovanja oštećenja pristupa se analizi uzročnika pomenutih oštećenja [2].

\subsubsection{Analiza oštećenja fasade}

Glavna fasada objekta je jedina bila dostupna za pregled. Fasada je uglavnom u dobrom stanju, iako je uočeno niz oštećenja kao što su prsline različitih uzročnika, otpadanje završnog sloja maltera, i razna oštećenja od mehaničkih udara.

Karakteristične horizontalne prsline pri dnu zidova fasade pojavile su se tačno na spoju dva različita elementa i to im je i uzrok nastajanja (betonska podna ploča prizemlja i noseći zid debljine $25 \mathrm{~cm}$ ). Kose prsline koje se javljaju oko otvora uzrokovane su promenom geometrije i koncentracijom napona, dok su vertikalne prsline duž otvora posledica vlage. Vlaga se skuplja oko otvora (prozori su izuzetno stari) ili se uvlači ispod zaštitnog sloja maltera ulazeći kroz druge prsline, stvarajući tako nove prsline. Kose prsline, koje su primećene na zidovima, su posledica sleganja temelja objekta (naknadno je izgrađen objekat neposredno do Noviteta, doprinoseći tako sleganju tog dela objekta). Ljuskanje i otpadanje zaštitnog sloja betona u donjim delovma zida se pojavilo usled kapilarnog penjanja vode. Podzemna voda se kapilarno penje u zidu u kom se javljaju naponi usled kristalizacije soli i/ili ciklusa zamrzavanja i odmrzavanja vode.

Na zidovima su takođe uočena i mehanička oštećenja čiji su uzroci razni - probijanje rupa u zidovima zarad izvođenja određenih instalacija, instaliranje oluka i povezivanje sa konstrukcijom, mehanički udari nepoznatog porekla, itd. Razlog otpadanja sloja matera kod betonskih ploča i venca jeste takođe vlaga, neadekvatno odvedena sa krova. Ova vlažna sredina takođe stvara pogodne uslove za razvoj biološke korozije [2].

\subsubsection{Analiza oštećenja unutrašnjosti objekta}

Stanje unutrašnjosti jako zavisi od dela koji je pregledan. Dok su spratovi i pojedini delovi prizemlja u dobrom stanju (zbog pravilnog održavanja), postoje delovi u prizemlju koji su u izuzetno lošem stanju. U unutrašnjosti su registrovana karakteristična oštećenja koja su u nastavku opisana.

Glavna oštećenja primećena na unutrašnjim zidovima jesu prsline i ljuskanje sloja maltera oko prozora, posledica neodržavanja i dotrajalosti prozora koji propuštaju vodu u unutrašnjost objekta. Karakteristična su takođe oštećenja pri dnu zidova nastala usled kapilarnog penjanja vode i kristalizacije soli. Često se javlja i promena boje zida, kao i biološka korozija. Na zidovima vlaga takođe pravi problem i u obliku kondenzovane vode ili vode iz kanalizacionih instalacija.

Kao i kod zidova, najveći preoblem na međuspratnoj TM tavanici jeste vlaga. Javljaju se karateristična oštećenja ljuskanja završnih slojeva, prsline, kao i izrazita promena boje i biološka korozija. Uzrok ovome jeste pucanje instalacionih cevi, procurivanje vode sa viših spratova $i$ krova (II sprat) [2]. 


\subsection{Zaključak o stanju objekta}

Iz priložene analize oštećenja i njihovih uzroka, zaključuje se da je glavni problem objekta „Novitet” vlaga, odnosno neodržavanje. Veliki broj oštećenja proizilazi iz činjenice da su prozori vrlo stari, neodržani i lako propuštaju vodu. Veliki problem takođe stvara podzemna voda. Objekat je imao malih problema sa sleganjem u periodu građenja susednog objekta, ali registrovana oštećenja nemaju značajan uticaj na nosivost tog dela konstrukcije. Može se zaključiti da je trajnost objekta izuzetno smanjena, dok stabilnost i nosivost nisu narušene. Funkcionalnost pojedinih prostora zavisi od stepena njihovog održavanja [2].

\section{PRORAČUN ENERGETSKE EFIKASNOSTI TRENUTNOG STANJA OBJEKTA}

Elaborat energetske efikasnosti, odnosno proračun energetske efikasnosti, je izrađen prema važećem Pravilniku o energetskoj efikasnosti zgrada, „Službeni glasnik RS“ br. 061/2011, objavljen 19.08.2011. godine.

Definisano je 26 netransparentnih pozicija, od toga 14 spoljašnjih zidova, 3 zida na dilataciji, 4 zida na granici grejanog i negrejanog prostora, 2 poda na tlu, krovna ploča i 2 drvenih vrata. Transparentnih pozicija ima ukupno 12 i to 9 prozora i 3 vrata. Odrađen je proračun građevinske fizike za svaku od pozicija (prolaz temperature, difuzija vodene pare, proračun letnje stabilnosti). U tebeli 1 su date vrednosti koeficijenta prolaska toplote $\mathrm{U}$, po pozicijama, i da li ispunjavaju uslov o najvećem dozvoljenom koeficijentu U [1].

Nakon toga, izačunati su toplotni transmisioni ventilacioni gubici i dobici od sunčevog zračenja i unutrašnjih izvora. Ustanovljeno da su gubici energije kroz netransparentne elemente i ventilacioni gubici (slika 3) najveći.

$\mathrm{Na}$ kraju je izračunata ukupna potrebna energija za grejanje za sistem koji radi bez prekida, kao i po mesecima. Na osnovu ovoga se zgrada svštava u energetski razred i u slučaju objekta Novitet, to je energetski razred $\mathrm{G}$.

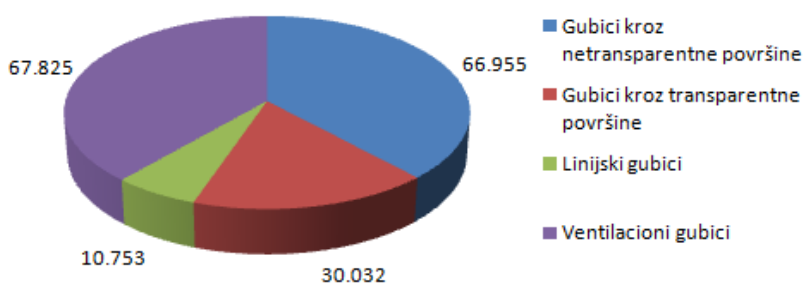

Slika 3. Energetski gubici na postojećem objektu

\section{MERE ENERGETSKE SANACIJE I PRORAČUN ENERGETSKE EFIKASNOSTI SANIRANOG STANJA OBJEKTA}

Sanacija objekta se sprovodi prema najvećim gubicima. U ovom slučaju sanirani su svi spoljni zidovi, ravan krov, urađena je zamena svih prozora na objektu (najveći gubici su ventilacioni $\mathrm{i}$ transmisioni kroz netransparentne elemente).

Usvojeno je da svi spoljašnji zidovi budu obloženi novom ventilisanom fasadom, sistema Aquapanel. Kao izolacioni materijal izabrana je meka kamena vuna. Budući da je zaštitni sloj maltera na fasadi u relativno dobrom stanju, on se neće uklanjati, nego se kamena vuna direktno nanosi na sloj maltera. Debljina kamene vune se određuje tako da bude ispunjen uslov o koeficijentu prolaza toplote i ona je za spoljašnje zidove usvojena debljine $8 \mathrm{~cm}$ [4].

Tabela 1. Vrednosti koeficijenta prolaska toplote najveći

\begin{tabular}{|c|c|c|c|c|}
\hline Element & Pozicija & $U\left(W / m^{2} K\right)$ & $\begin{array}{c}U_{\max } \\
\left(W / m^{2} K\right) \\
\end{array}$ & $\begin{array}{c}\text { Uslov } \\
\text { zadovoljen }\end{array}$ \\
\hline \multirow{14}{*}{$\begin{array}{l}\text { Spoljašnji } \\
\text { zidovi }\end{array}$} & SZ1 & 1.292 & 0.4 & $\mathrm{Ne}$ \\
\hline & SZ2 & 1.063 & 0.4 & $\mathrm{Ne}$ \\
\hline & SZ3 & 1.369 & 0.4 & $\mathrm{Ne}$ \\
\hline & SZ4 & 1.352 & 0.4 & $\mathrm{Ne}$ \\
\hline & SZ5 & 1.33 & 0.4 & $\mathrm{Ne}$ \\
\hline & SZ6 & 2.542 & 0.4 & $\mathrm{Ne}$ \\
\hline & SZ7 & 2.484 & 0.4 & $\mathrm{Ne}$ \\
\hline & SZ8 & 2.41 & 0.4 & $\mathrm{Ne}$ \\
\hline & SZ9 & 2.962 & 0.4 & $\mathrm{Ne}$ \\
\hline & SZ10 & 1.244 & 0.4 & $\mathrm{Ne}$ \\
\hline & SZ11 & 1.23 & 0.4 & $\mathrm{Ne}$ \\
\hline & SZ12 & 2.488 & 0.4 & $\mathrm{Ne}$ \\
\hline & SZ13 & 2.718 & 0.4 & $\mathrm{Ne}$ \\
\hline & SZ14 & 2.785 & 0.4 & $\mathrm{Ne}$ \\
\hline \multirow{3}{*}{$\begin{array}{l}\text { Zidovi na } \\
\text { dilatacijama }\end{array}$} & ZD1 & 1.229 & 0.5 & $\mathrm{Ne}$ \\
\hline & ZD2 & 1.02 & 0.5 & $\mathrm{Ne}$ \\
\hline & ZD3 & 2.649 & 0.5 & $\mathrm{Ne}$ \\
\hline \multirow{4}{*}{$\begin{array}{l}\text { Zidovi ka } \\
\text { negrejanom } \\
\text { prostoru }\end{array}$} & UZ1 & 0.97 & 0.55 & $\mathrm{Ne}$ \\
\hline & UZ2 & 2.339 & 0.55 & $\mathrm{Ne}$ \\
\hline & UZ3 & 1.158 & 0.55 & $\mathrm{Ne}$ \\
\hline & UZ4 & 1.146 & 0.55 & $\mathrm{Ne}$ \\
\hline \multirow{2}{*}{ Podovi na tlu } & PT1 & 0.403 & 0.4 & $\mathrm{Ne}$ \\
\hline & PT2 & 0.324 & 0.4 & $\mathrm{Da}$ \\
\hline Krovna ploča & KP1 & 0.904 & 0.2 & $\mathrm{Ne}$ \\
\hline \multirow{9}{*}{ Prozori } & PR1 & 2.76 & 1.5 & $\mathrm{Ne}$ \\
\hline & PR2 & 3.5 & 1.5 & $\mathrm{Ne}$ \\
\hline & PR3 & 3.5 & 1.5 & $\mathrm{Ne}$ \\
\hline & PR4 & 3.5 & 1.5 & $\mathrm{Ne}$ \\
\hline & PR5 & 5 & 1.5 & $\mathrm{Ne}$ \\
\hline & PR6 & 3.5 & 1.5 & $\mathrm{Ne}$ \\
\hline & PR7 & 3.5 & 1.5 & $\mathrm{Ne}$ \\
\hline & PR8 & 5 & 1.5 & $\mathrm{Ne}$ \\
\hline & PR9 & 3.5 & 1.5 & $\mathrm{Ne}$ \\
\hline \multirow{5}{*}{ Vrata } & VR1 & 2.5 & 1.5 & $\mathrm{Ne}$ \\
\hline & VR2 & 2.904 & 1.5 & $\mathrm{Ne}$ \\
\hline & VR3 & 3.045 & 1.5 & $\mathrm{Ne}$ \\
\hline & VR4 & 2.194 & 1.5 & $\mathrm{Ne}$ \\
\hline & VR5 & 2.163 & 1.5 & $\mathrm{Ne}$ \\
\hline
\end{tabular}

Umesto postojećih ravnih krovova izvode se novi zeleni krovovi tipa Urbanscape. Pre izvođenja novih slojeva krova potrebno je prvo ukloniti sve slojeve starog krova, do konstrukcije. Kao toplotna izolacija opet je izabrana kamena vuna, dok je za parnu branu izabrana Knauf LDS 200.

Hidroizolacija je bitumeska. Potrebna debljina kamene vune je određena i usvojena u vrednosti od $16 \mathrm{~cm}$ [5].

Svi transparantni elementi se zamenjuju. Tip stakla korišćen za elemente je dvostruko, niskoemisiono, 4-12-4 $\mathrm{mm}$ (Kr), dok je okvir od PVC-a (6-komorni).

Ponovno je sproveden proračun energetske efikasnosti prema važećem Pravilniku o energetskoj efikasnosti zgrada, „Službeni glasnik RS“ br. 061/2011, objavljenim 19.08.2011. godine, ali za novodefinisane sklopove. Nakon proračuna građevinske fizike i proračuna gubitaka, uviđa se da su znatno smanjeni gubici kroz netransparentne i transparentne elemente, kao i ventilacioni gubici (slika 4). 


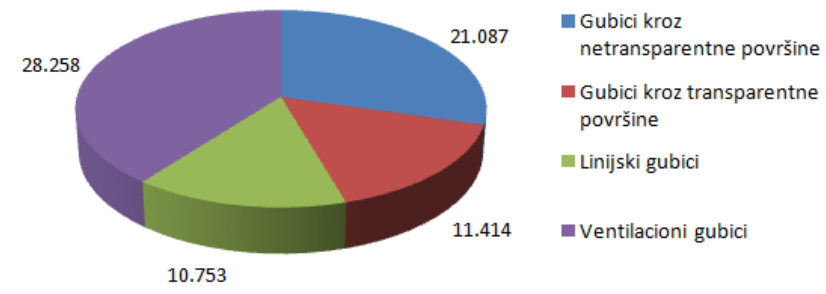

Slika 4. Energetski gubici na saniranom objektu

Nakon proračuna dobitaka, i potrebne energije za grejanje objekta ogređen je novi energetski razred objekta, C.

\section{ZAKLJUČAK}

U praktičnom delu rada izvršena je procena stanja objekta i zaključeno je kako, iako stabilnost i nosivost objekta nisu narušene, trajnost objekta jeste. Pristupljeno je proračunu gde je objekat kategorizovan u energetski razred $G$, najlošiji. Kako bi se $u$ isto vreme povećala trajnost objekta, ali i smanjila količina energije potrebne za zagrevanje objekta popravljene su karakteristike određenih elemenata objekta.

Spoljni zidovi su popravljeni Aquapanel ventilisanom fasadom, detaljnije opisanoj u teorijskom delu rada, koja u isto vreme bolje toplotno izoluje objekat, a i štiti objekat od atmosferilija, time mu povećavajući trajnost, i ukloniti glavni uzročnik oštećenja u objektu, vlagu. Krov je izveden kao zeleni (Urbanscape), dok su prozori takođe zamenjeni novima, sa boljim izolacionim karakteristikama.

Nakon ponovljenog proračuna energetske efikasnosti na saniranom objektu, on je svrstan u energetski razred $\mathrm{C}$. Budući da se energetska sanacija jednog objekta smatra uspešnom ako se energetski razred podigne za jedan, ova sanacija se smatra uspešnom. Na slici 5. prikazana je potrebna količina energije za zagrevanje postojećeg, i saniranog objekta po mesecima.

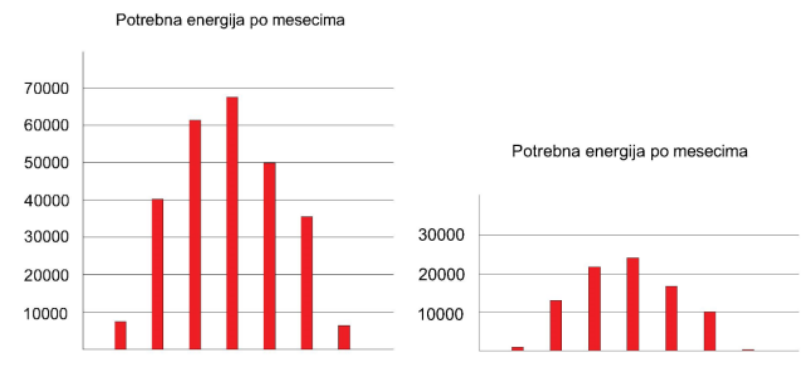

Slika 5. Potrebna energija za zagrevanje postojećeg $i$ energetski saniranog objekta

\section{LITERATURA}

[1] Inženjerska komora Srbije, "Pravilnik o energetskoj efikasnosti zgrada, "Sl.glasnik RS", br.61/2011", Beograd"

[2] Malešev M., Radonjanin V., "Oštećenja i sanacija zidanih, čeličnih i drvenih konstrukcija, Skripta sa predavanja”, Fakultet tehničkih nauka, Novi Sad

[3] https://www.knaufinsulation.rs/ventilisana-fasada

[4] http://www.knauf.rs/wpcontent/uploads/2020/07/WL132C.1_1.0_web.pdf

[5] https://www.knaufinsulation.rs/zeleni-krovovi

\section{Kratka biografija:}

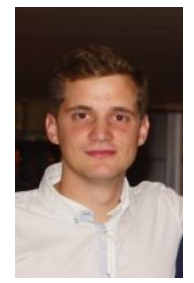

Jakov Budimac rođen je u Novom Sadu 1995. god. Master rad na Fakultetu tehničkih nauka iz oblasti Građevinarstvo - Konstrukcije, procena stanja i sanacija betonskih konstrukcija odbranio je 2020.god.

kontakt: budimacjakov@gmail.com 